M. F. A. ADAMO,* J. E. BALDWIN, R. M. ADLINGTON (OXFORD UNIVERSITY, UK) Application of Bis-acetylenic Ketones in Synthesis: One-Pot Preparation of the 1,2,4-Triazepine and Oxatriazaindenone Cores

J. Org. Chem. 2005, 70, 3307-3308.

\title{
Bis-acetylenic Ketones for the Synthesis of 1,2,4-Triazepine and Oxatriazaindenone Cores
}<smiles></smiles>

Significance: Bis-acetylenic ketones are used for the efficient (88-91\%) one-pot synthesis of triazepine and oxa-triazaindenone cores representing two unusual heterocycles. The reactions are convenient, high yielding, and modular; therefore, they could be useful tools for the rapid generation of families of complex, diverse, and dense heterocyclic building blocks.
Comment: Amidrazones possessing three nitrogen nucleophiles are essential components of molecules exhibiting high biological activities, e.g. Lamotrigine and Sildenafil (Viagra). The work represents an extension of the modular Click Chemistry (H. C. Kolb; K. B. Sharpless Drug Discovery Today 2003, 8, 1128-1137) that uses only very practical and robust organic transformations in which multicomponent reactions and one-pot procedures play a vital role. In this study, the regiochemical control observed is due to the presence of the carbethoxy group which governs the relative reactivity of the two triple bonds. Based on this result, variation of the highly reactive bis-acetylenic ketone derivatives for reactions with multiple nucleophilic systems may be anticipated. 